\title{
The equatorial F-layer: progress and puzzles
}

\author{
H. Rishbeth \\ Department of Physics and Astronomy, University of Southampton, Southampton SO17 1BJ, United Kingdom \\ e-mail: hr@phys.soton.ac.uk
}

Received: 20 October 1999 / Revised: 13 March 2000 / Accepted: 20 March 2000

\begin{abstract}
This work reviews some aspects of the ionospheric F-layer in the vicinity of the geomagnetic equator. Starting with a historical introduction, brief summaries are given of the physics that makes the equatorial ionosphere so interesting, concentrating on the large-scale structure rather than the smaller-scale instability phenomena. Several individual topics are then discussed, including eclipse effects, the asymmetries of the 'equatorial trough', variations with longitude, the semiannual variation, the effects of the global thermospheric circulation, and finally the equatorial neutral thermosphere, including 'superrotation' and possible topographic influences.
\end{abstract}

Key word: Ionosphere (equatorial ionosphere)

\section{Introduction}

Ever since its peculiarities were first noticed sixty years ago, the equatorial ionosphere has been the venue of many ground-based and space-based experiments, the subject of much speculation, the topic of innumerable papers, and the source of much interesting physics. It is fitting for it to be represented in this volume that celebrates the scientific career of Lance Thomas, whose contributions to ionospheric science include studies of the equatorial region (Lyon and Thomas, 1963; Thomas, 1968).

The strong ionospheric electric current known as the equatorial electrojet was originally detected by its magnetic effect, observed by ground-based magnetometers (McNish, 1937; Egedal, 1948). Geomagnetic measurements in the equatorial region have a long history, especially in India where observations started as early as 1822, as described by Rajaram and Pisharoty (1998). Observatories near the magnetic equator were established at Trivandrum in 1841 and Kodaikanal in 1902, though they have not functioned continuously since then. The Huancayo observatory in Peru was established in 1922, and the adjacent ionosonde station began recording in 1938 and has operated ever since. The 50 $\mathrm{MHz}$ incoherent scatter radar at Jicamarca near Lima began operating in 1961 (Farley, 1991), being especially valuable for its capability of measuring ionospheric drift velocity (Woodman, 1970). Ionospheric observatories were established near the geomagnetic equator at Ibadan in Nigeria in 1951, and at Trivandrum and Thumba in India in 1957. (The dates for ionosonde stations refer to the earliest data in the World Data Centre catalogue.)

Ground-based studies of the ionosphere have always been limited by the distribution of ionosondes and other instruments. The equatorial region is comparatively well off because of the incoherent and coherent radars at Jicamarca, Trivandrum, and Kwajalein, the rocket ranges in Guyana, Brazil and India, and several optical observing sites, augmented by shipborne and airborne observations on a campaign basis. More importantly, for the purpose of delineating the equatorial anomaly, there are (or at least, in the IGY and IQSY there were) threeand-a-half latitudinal chains of ionosondes: the American, African, and East Asian/Australasian chains embracing both magnetic hemispheres and the Indian chain covering the northern side only. Topside sounders and beacon satellites have proved powerful tools for measuring the critical frequency $f_{\mathrm{OF}} 2$ and the total column electron content. Satellite-borne in-situ instruments yield vast datasets, though their use for studying F2-layer electron density is influenced by the fact that satellite trajectories do not follow the height of the F2 peak.

It soon became apparent that, within a few degrees of the geomagnetic equator, the ionosphere has features that are not found elsewhere. The daytime E-layer contains highly irregular structures that are associated with the electrojet, and cause equatorial sporadic E. The F-layer displays striking variations of F-layer electron density and height, especially before sunrise and around sunset (Fig. 1). The variations at sunset are generally 


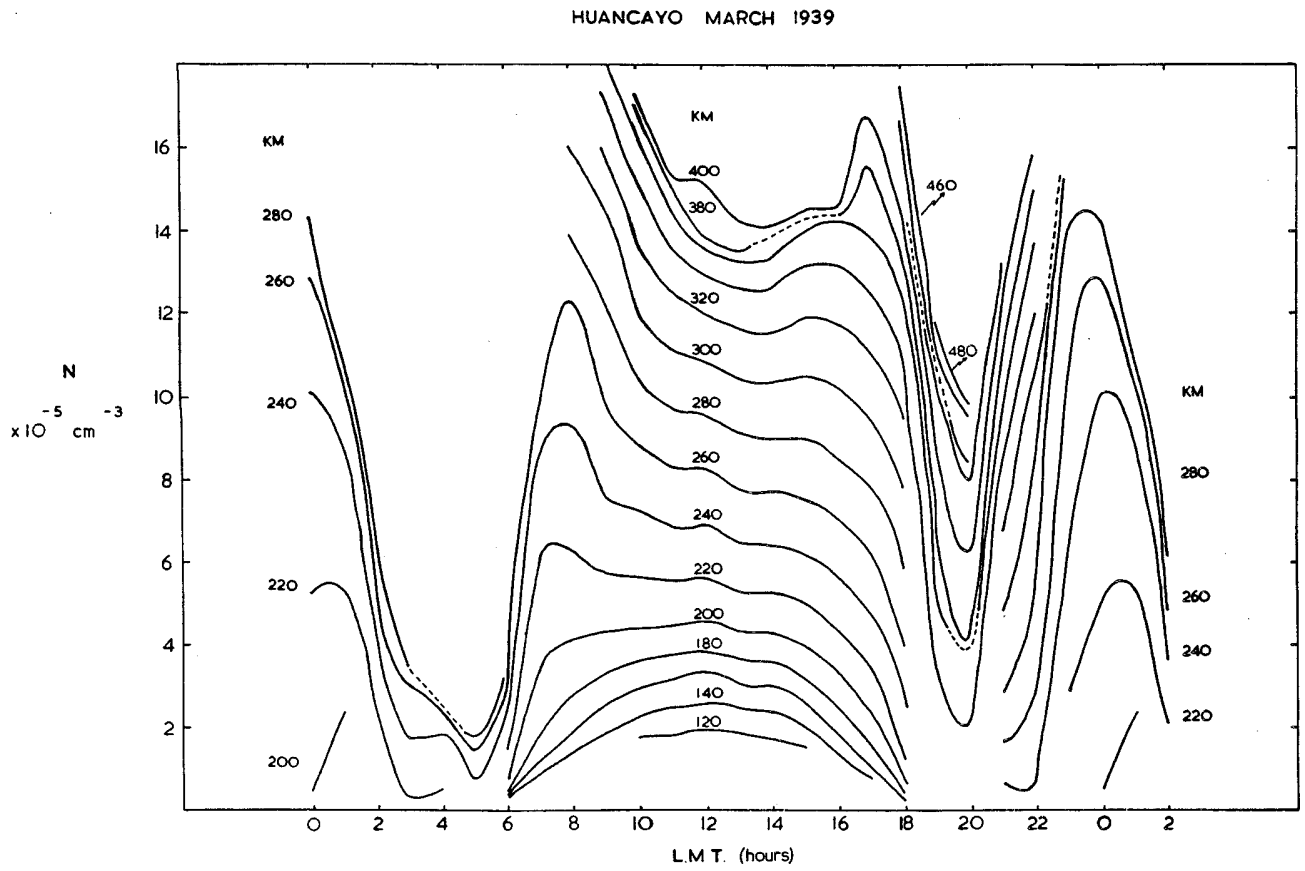

Fig. 1. Electron density $N(h, t)$ distributions in height and local time at Huancayo, quiet days in March 1939, from Croom et al. (1959) accompanied by the instability phenomenon known as equatorial spread $\mathrm{F}$.

The latitudinal variations are peculiar, too. It was the Japanese scientists who, comparing the midday F2-layer critical frequency $f_{\mathrm{oF}} 2$ from stations at different latitudes, discovered the equatorial trough or anomaly. Fig. 2, adapted from Namba and Maeda (1939), is based on 1937/1938 data from five ionosonde stations; the authors doubled their data points by assuming seasonal symmetry about the geographic equator (see figure caption). It must be pointed out that the 'trough' in Fig. 2 appears mainly because Huancayo $f_{\mathrm{O}} \mathrm{F} 2$ is

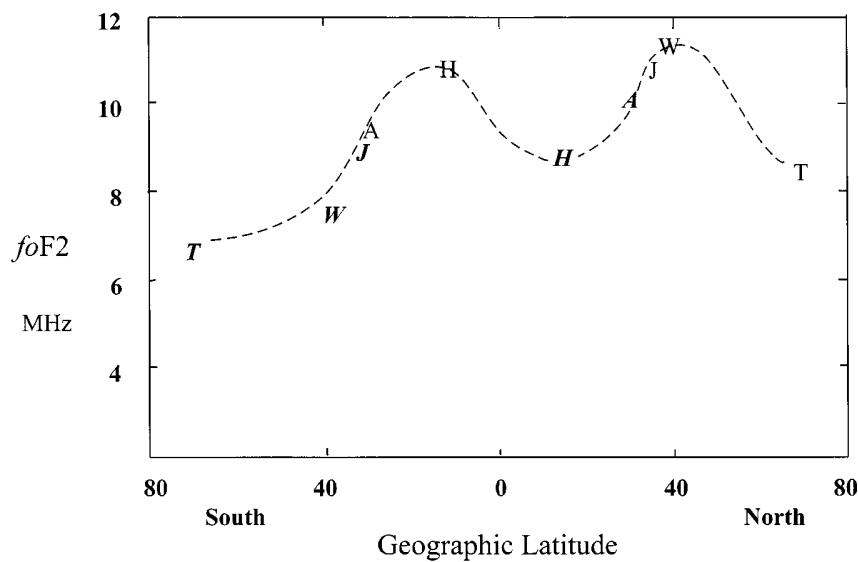

Fig. 2. Midday critical frequency $f_{\mathrm{O}} \mathrm{F} 2$ at solstice in $1937 / 38$, using data from Tromsø $\left(T, 70^{\circ} \mathrm{N}\right)$, Washington $\left(W, 39^{\circ} \mathrm{N}\right)$, Hiraiso $\left(J, 36^{\circ} \mathrm{N}\right)$, Huancayo $\left(H, 12^{\circ} \mathrm{S}\right)$, and Watheroo $\left(A, 30^{\circ} \mathrm{S}\right)$. The roman letters show December/January values from the northern stations and June/July data from the southern stations, plotted in their correct hemispheres. The italic letters show June/July values from the northern stations and December/January values from the southern stations, plotted in their opposite hemispheres. After Namba and Maeda (1939) greater in December than in June, so it is not really a geomagnetic effect (the corresponding equinox data do not show a trough), and that the five stations are at very different longitudes. However, wartime operational reports for the Pacific region show the equatorial trough clearly. The Japanese priority in this matter was pointed out by Bailey (1948), though the equatorial feature is often called the Appleton anomaly because its first description in a widely available Western journal was by Appleton (1946), who may have been aware of the Japanese work. Generally speaking, the trough exists from mid-morning to late evening, and is aligned with the geomagnetic dip equator, where the peak electron density $N \mathrm{mF} 2$ is typically $30 \%$ or so less than at the 'crests' which lie $15^{\circ}-20^{\circ}$ to the north and south. The depth of the trough varies considerably with place, local time, season and with solar and geomagnetic activity.

Many review papers exist that deal with the equatorial F-layer, its morphology and its dynamics, for example Rastogi et al. (1972), Rajaram (1977), Rishbeth (1977), Moffett (1979) and Fejer (1981, 1991, 1997). The present study is not intended to be a comprehensive review. Its purpose is to recall the characteristics that make the equatorial F-layer so interesting, to review a selection of observational and theoretical advances in its study, including some new discussion and a little new analysis of a clearing-up nature, and to point out some problems that remain. The work does not review magnetic storm effects, and deals only with the large-scale structure (tens and hundreds of kilometres). This does place limitations on the scope of the discussion, because the equatorial ionosphere is a fascinating plasma laboratory, more so than any other part of the ionosphere, except perhaps the auroral zones, and much of the physics of the large-scale structure is linked with the smaller-scale plasma irregularities and instabilities; see for example Kelley (1989) and Kelley and Hysell (1991). 


\section{Why the equatorial ionosphere is so interesting: some theoretical ideas}

Ionospheric behaviour is controlled by physical processes which are largely expressed in terms of conservation equations for mass, momentum and energy. The equatorial ionosphere is special because of the constraint imposed on charged particle motions by the geomagnetic field. As a result, the equations are complicated by the magnetic field geometry that must be incorporated in them. To expand on the present simple discussion, further details may be found in standard ionospheric textbooks.

\subsection{Equations of continuity}

In the equatorial F2-layer the continuity equation for the electron and ion density (or concentration), $N$, takes the well-known form

$\partial N / \partial t=q-\beta N-\operatorname{div}(N \mathbf{V})$

where $q$ is the production rate, $\beta$ is the linear loss coefficient, and $\mathbf{V}$ is the plasma drift velocity. The transport term can be expanded as:

$\operatorname{div}(N \mathbf{V})=N \operatorname{div} \mathbf{V}+\mathbf{V} \cdot \operatorname{grad} N$

which shows that the effect of drift on the electron density depends partly on the velocity divergence and partly on the advection (movement) of a pre-existing gradient of electron density. In the equatorial ionosphere there are often pronounced horizontal gradients of electron density, and horizontal plasma motions play a greater part in shaping the ionosphere, through the $(\mathbf{V} \cdot \operatorname{grad} N)$ term, than they do in the midlatitude ionosphere, where horizontal gradients are seldom important except in special situations such as at sunrise (Rüster and Dudeney, 1972).

\subsection{Causes of plasma motion}

The plasma velocity $\mathbf{V}$ has terms due to electric fields $(\mathrm{E})$, neutral air winds $(\mathrm{W})$, and plasma diffusion (D):

$\mathbf{V}=\mathbf{V}_{\mathrm{E}}+\mathbf{V}_{\mathrm{W}}+\mathbf{V}_{\mathrm{D}}$

The first term, the electromagnetic drift term, takes the familiar form

$\mathbf{V}_{\mathrm{E}}=(\mathbf{E} \times \mathbf{B}) / B^{2}$

The geomagnetic field (flux density $\mathbf{B}$ ) points horizontally and essentially northward at equatorial latitudes, so a west-to-east electric field $E_{\mathrm{x}}$ produces upward plasma drift and a vertically upward field $E_{\mathrm{z}}$ produces westward drift. The importance of the electromagnetic drift term in the continuity Eq. (1) usually depends on the advection term $\left(\mathbf{V}_{\mathrm{E}} \cdot \operatorname{grad} N\right)$; the divergence term in Eq. (2) is small because

$$
\begin{aligned}
\operatorname{div} \mathbf{V}_{\mathrm{E}}= & (\mathbf{B} \cdot \operatorname{curl} \mathbf{E}-\mathbf{E} \cdot \operatorname{curl} \mathbf{B}) / B^{2} \\
& +(\mathbf{E} \times \mathbf{B}) \cdot \operatorname{grad}\left(1 / B^{2}\right) \approx 0
\end{aligned}
$$

Here curl $\mathbf{E}=0$ because $\mathbf{E}$ is a potential field, and curl $\mathbf{B}$ practically vanishes because the current density is very small in the F-layer. The remaining term in Eq. (5) is also fairly small because it depends on the spatial variations of $B$, which are of scale size $\sim 1000 \mathrm{~km}$. Nevertheless, Raghavarao et al. (1984) conclude that spatial variations in electric field, of scale size $\sim 15 \mathrm{~km}$, must exist to explain the observed drifts of ionized barium clouds at heights of $180-200 \mathrm{~km}$ in the twilight equatorial ionosphere. These variations must be consistent with the divergence-free nature of $\mathbf{V}_{\mathrm{E}}$.

The second term, the wind term, expresses the fact that the neutral air wind $\mathbf{U}$ can drive the F-layer plasma only along the geomagnetic field lines, at a speed equal to the wind component in that direction, which may be written vectorially as

$\mathbf{V}_{\mathrm{W}}=(\mathbf{U} \cdot \mathbf{B}) \mathbf{B} / B^{2}$

Like $\mathbf{V}_{\mathrm{E}}, \mathbf{V}_{\mathrm{W}}$ has small divergence.

The third term is the plasma diffusion term. The plasma diffusion velocity depends on the plasma diffusion coefficient $D$, on gravity, and on the first-order and second-order derivatives of plasma concentration and temperature in the direction of the geomagnetic field. The plasma diffusion term in the continuity equation then takes the form

$-\operatorname{div}\left(N \mathbf{V}_{\mathrm{D}}\right)=D \mathscr{D} N$

where $\mathscr{D}$ is a complicated differential operator, involving first and second derivatives with respect to dipole coordinates. It was derived algebraically by Kendall (1962) and others for the special case of an isothermal atmosphere and a dipole magnetic field. For the midlatitude case, with straight field lines at dip angle $I$, the operator $\mathscr{D}$ reduces to the form derived by Ferraro (1945), with an effective coefficient for vertical diffusion, $D \sin ^{2} I$. It later became feasible to adopt improved geometry, such as apex coordinates (Van Zandt et al., 1972), in the diffusion equation, and to incorporate the International Geomagnetic Reference Field, as did Chan and Walker (1984a, b) for the East Asian sector, and later in the fully interactive thermosphereionosphere coupled model (Richmond et al., 1992).

\subsection{Neutral air winds}

The horizontal wind velocity $\mathbf{U}$ resulting from the horizontal pressure gradients depends on the Coriolis force due to the Earth's rotation (angular velocity $\Omega$ ), on the molecular viscosity of the air, and on the ion-drag due to collisions between air molecules and the ions. The equation of motion for the horizontal wind is

$\mathrm{d} \mathbf{U} / \mathrm{d} t=\mathbf{F}-2 \Omega \times \mathbf{U}+K N(\mathbf{V}-\mathbf{U})+(\mu / \rho) \nabla^{2} \mathbf{U}$

where

$\mathrm{d} \mathbf{U} / \mathrm{d} t=\partial \mathbf{U} / \partial t+(\mathbf{U} \cdot \nabla) \mathbf{U}$

As gravity is omitted (being almost precisely balanced by the vertical pressure-gradient force), Eq. (8) applies only to the horizontal wind, $\mathbf{F}$ denoting the horizontal 
component of the force per unit mass due to the pressure-gradient

$\mathbf{F}=-(1 / \rho) \nabla_{\text {horiz }} p$

where $\rho$ is the air density, $\mu$ is the coefficient of molecular viscosity, $K$ is the collision parameter (rate coefficient for ion-neutral collisions) and $K N$ is the neutral-ion collision frequency. Besides these terms, a term denoting tidal effects may be added, or else incorporated in the pressure-gradient term (as here). The viscosity term is important in the F-layer because it smooths out the vertical variation of wind velocity, although it does not play any particular part in the present discussion.

Ion-drag exists because the ions, being constrained by the geomagnetic field, cannot move freely with the wind. Clearly, ion-drag term only operates if the plasma drift velocity $\mathbf{V}$ (which in this case, is effectively the ion velocity) differs from the neutral air wind $\mathbf{U}$, the difference being largely determined by the geomagnetic field. Eq. (8) shows that, if the ions are set in motion by electromagnetic forces, ion-drag then acts as a driving force on the neutral air.

\subsection{The equatorial fountain}

Early in the development of F-layer dynamics, it was realized that the formation of the equatorial trough must have something to do with plasma diffusion along magnetic field lines. Mitra (1946) suggested that the trough exists because plasma, produced by photoionization at great heights over the magnetic equator, diffuses downwards and outwards to the north and south, leaving a depletion at the equator. Since the geomagnetic field lines passing through the F-layer crests (at about $15^{\circ}-20^{\circ}$ magnetic latitude) cross the equator at about $800-1000 \mathrm{~km}$ height, where the production rate $q$ is small, some other source of plasma seems necessary. Martyn (1947) and Duncan (1960) envisaged that the plasma comes from lower levels in the F2-layer; it is lifted to great heights by the eastward electric fields that exist in low latitudes by day, and then diffuses downward along field lines, as Mitra (1946) suggested. As Kendall and Pickering (1967) say, "The electron-ion pairs may be thought of as sliding down the magnetic field lines with a diffusive motion, while at the same time the whole field line drifts at right angles to itself." When computing power became equal to the task of handling the diffusion equation with dipole geometry, it was confirmed that the Mitra process is inadequate on its own (Rishbeth et al., 1963), and also that Martyn's theory can account for a trough such as observed, with daytime upward drifts of order $10 \mathrm{~m} \mathrm{~s}^{-1}$ (Bramley and Peart, 1965; Hanson and Moffett, 1966; Bramley and Young, 1968). The development of the theory has been well reviewed by Moffett (1979). Because the upward and outward flow of plasma has been likened to an electrically driven fountain, the process is now known as the fountain effect, though the flow lines of the plasma are more horizontal than vertical, and do not really look like one's idea of a fountain (Fig. 3). Furthermore, despite the impression of long-distance transport that the 'fountain' analogy might suggest, any given ionelectron pair only travels a few tens of kilometres during its lifetime of order $1 \mathrm{~h}$. Hanson and Moffett (1966) also modelled a 'reverse fountain', which produces an equatorial ridge of electron density. Since the 24-h average of vertical drift velocity must be zero, the upward drift by day must be balanced by a downward drift at night, so the 'reverse fountain' must then occur. However, as photoionization is absent at night, the effects of the 'reverse fountain' may differ from that shown by the Hanson and Moffett (1966) calculations.

\subsection{Modelling the equatorial F-layer}

As just mentioned, computer modelling of the equatorial F2-layer, based on solutions of the continuity Eq. (1) with equatorial diffusion operator, started in the 'sixties'. The models referred to in Sect. 2.4 were steadystate, but time-varying models soon followed (Sterling et al., 1969). The earlier computations assumed simple fixed models of the neutral thermosphere, but it later became possible to adopt more sophisticated thermospheric models such as the well-known MSIS model (e.g. Chan and Walker, 1984a, b).

The first coupled thermosphere-ionosphere interactive models avoided the difficult problem presented by the equatorial F2-layer, by resorting at low latitudes to a prescribed model of the electron density distribution, such as that of Chiu (1975), and of the electric field (Richmond et al., 1980). Later it became possible to include the equatorial zone in the computations, with fully self-consistent dynamo calculations in which the E-region winds interact with the magnetic field and currents (Richmond et al., 1992; Richmond, 1995).

It may well be asked: given these complex interactive models with their enormous potentialities, what is the point in recalling the earlier work of some decades ago? An answer is that the older computations, which had to concentrate on one or two processes, demonstrate more clearly the effects of, say, a given pattern of drifts and

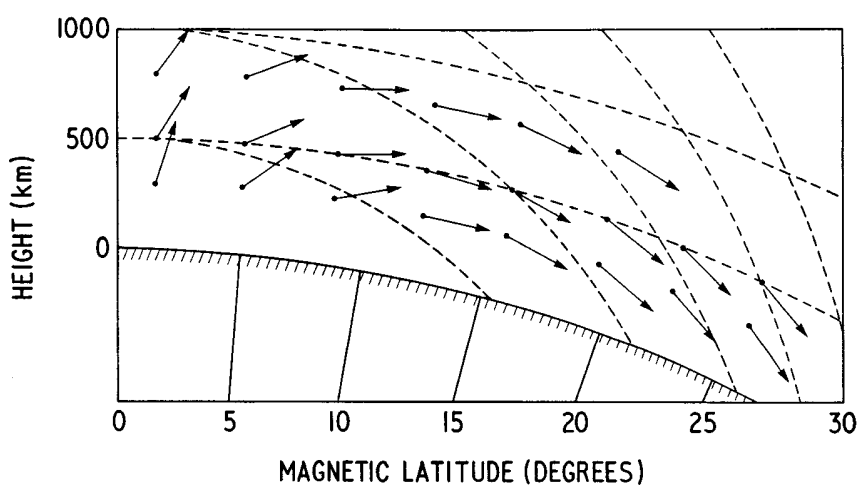

Fig. 3. The 'equatorial fountain': vector plot of plasma flow in the daytime F-layer. Five magnetic field lines, and also the fixed heights of 500 and $1000 \mathrm{~km}$, are shown by dashed lines. Adapted from Hanson and Moffett (1966) 
winds than is easily apparent from the output of more sophisticated models.

\section{Some aspects of equatorial F-layer morphology}

\subsection{Eclipses and photochemistry}

In a rather different type of modelling from that described in Sect. 2.5, Van Zandt et al. (1960) took advantage of the occurrence of an almost total solar eclipse at Danger Island ( $11^{\circ} \mathrm{S}$ geomagnetic latitude), and the lack of vertical diffusion near the magnetic equator, to investigate the production and loss terms $q$ and $\beta$ in the continuity equation. They deduced the following formulas from their analysis of the eclipse $N(h, t)$ curves at F2-layer heights:

$$
\begin{aligned}
& q(h)=8.8 \times 10^{8} \exp ((300-h) / 186) \quad\left[\mathrm{m}^{-3} \mathrm{~s}^{-1}\right] \\
& \beta(h)=6.8 \times 10^{-4} \exp ((300-h) / 103) \quad\left[\mathrm{s}^{-1}\right]
\end{aligned}
$$

These results were important because, being larger than the values generally believed at the time, they caused some rethinking of the question of photochemical rates. In fact, the values of $q$ and $\beta$ turned out to be reasonably consistent with earlier estimates, after making due allowance for the high solar flux rates and large scale heights prevailing at the very high solar activity of 1958 . The authors reasoned that their results were not significantly influenced by transport processes.

The $N(h, t)$ curves from another low-latitude eclipse (Fig. 4) show another feature, a bunching of the $N(t)$ curves that indicates a very small height gradient of electron density, i.e. the $N(h)$ profile is nearly vertical. This produces a 'cusp' on ionograms, the eclipse F1 1/2 layer, which rises as the eclipse progresses. The F1 1/2 layer is often prominent during solar eclipses, particularly at low latitudes where, according to Sterling et al. (1972), it is caused by the electromagnetic drift, rather

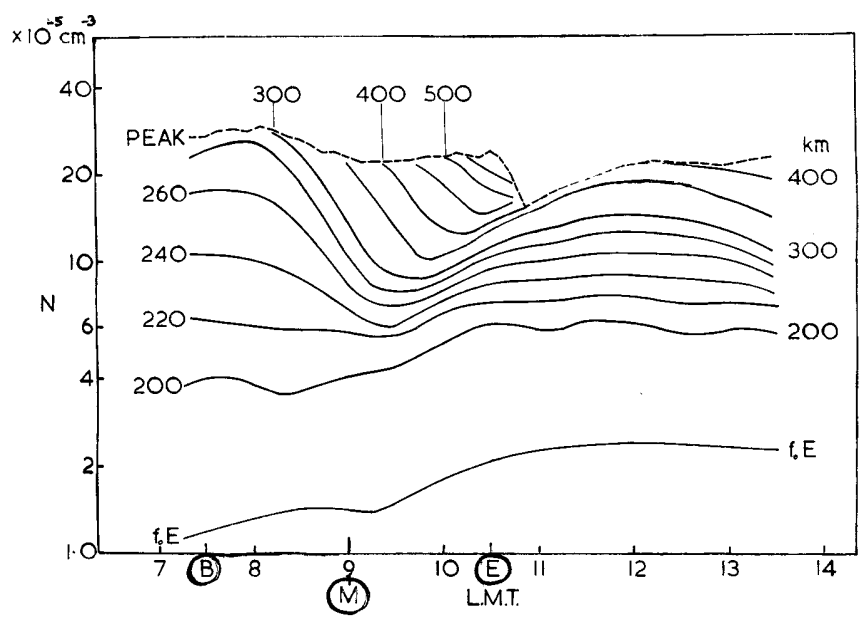

Fig. 4. Electron density $N(h, t)$ and the F2 peak electron density, recorded at Singapore $\left(1^{\circ} \mathrm{N}, 104^{\circ} \mathrm{E}\right)$ during the partial eclipse of 19 April 1958. Letters $B, M, E$ mark the beginning, maximum and end of the eclipse. (Radio Research Station/Rutherford Appleton Laboratory) than by an effect of F1 layer photochemistry, as is thought to be the case at midlatitudes (Ratcliffe, 1956). Another eclipse observation, made in 1966 by the Jicamarca radar, nicely demonstrates the electromagnetic drift: the 'hole' punched by the eclipse in the lower F2 layer subsequently drifts rapidly upwards (V.L. Peterson, private communication). These papers may perhaps be exceptions to a general rule that it is extremely difficult to derive reliable information on ionospheric processes from eclipse observations.

\subsection{Summer-winter asymmetries of the trough}

Among many studies using ionosonde data, Lyon and Thomas (1963) and Thomas (1968) analyzed quiet-day data from three ionosonde chains. They found that the latitude variation is asymmetrical at solstice, with $\mathrm{NmF} 2$ greater on the summer side of the magnetic equator at night and greater on the winter side by day. At 'true equinox', with the sun directly above the geographic equator, $f_{\mathrm{OF} 2}$ is symmetrical about the magnetic equator. In general this is not the case at 'dip equinox', with the sun over the magnetic dip equator (which occurs on different dates in different longitudes). The evening enhancements of $f \mathrm{oF} 2$ are more marked on the side nearest the geographic equator. Thomas (1968), using solstice data from 1958, studied the north-south asymmetries in the critical frequency $f_{\mathrm{OF}} 2$ and the height $h \mathrm{mF} 2$ of the F2 peak, derived partly from $N(h)$ analysis and also from the $M 3000$ propagation factor scaled from ionograms. In general $f_{\mathrm{oF}} 2$ is greater and $h \mathrm{mF} 2$ lower on the winter than on the summer side, in those sectors where the subsolar latitude is far from the magnetic equator, which means the American sector in June and the Afro-Asian sector in December. Conversely, in the American sector in December and the AfroAsian sector in June, when the subsolar latitude is closer to the magnetic equator (and lies within the trough), there is little or no asymmetry at midday, though the winter/summer asymmetries develop by the evening. In the Indian sector at least, the northern crest is at a higher dip latitude at solstice than at equinox, $18^{\circ}$ as compared to $14^{\circ}$ (Rastogi et al., 1972). The equatorial trough is more prominent and longer-lasting at solar maximum than at solar minimum, which may be due to differences in amplitude or local-time phase of the electromagnetic drift.

As just mentioned, the height of the F2 peak varies across the equatorial zone. In general $h \mathrm{mF} 2$ is highest at the equator, falling off slightly towards the summer side and more rapidly towards the winter side, the summer/ winter difference being around $100 \mathrm{~km}$ by day and $50 \mathrm{~km}$ at night. It is remarkable that the day/night variation of the height $h \mathrm{mF} 2$ at equatorial latitudes, though similar in amplitude to that at midlatitudes (of order $100 \mathrm{~km}$ ), is completely opposite in phase. At midlatitudes, $h \mathrm{mF} 2$ is higher at night than by day, because of the effect of the poleward thermospheric wind by day and equatorward wind at night. At the equator, however, $h \mathrm{mF} 2$ is largely controlled by the 
electromagnetic drift, which is upward by day and downward at night.

Most of the asymmetries seem broadly consistent with the expected effects of a geographically controlled system of horizontal winds, blowing outwards by day from the subsolar latitude. At solstice, the resulting transfer of plasma across the magnetic equator by the transequatorial wind enhances the daytime 'downwind crest'. As remarked by Hanson and Moffett (1966), this transfer overcomes an opposing tendency, namely that a transequatorial wind $U$ produces a vertical drift $U \sin I$ $\cos I$ that raises the 'upwind crest' and lowers the 'downwind crest'. This affects $N \mathrm{mF} 2$ because the loss coefficient $\beta$ in Eq. (1) is height-dependent.

\subsection{Local time variations of electron density}

The effect of neutral air winds on the local time variations of electron density were studied by AburRobb and Windle (1969), whose calculations assumed a steady transequatorial wind, and by Sterling et al. (1969), who assumed meridional winds symmetrical about the equator but diverging from it by day and converging at night, as in the global wind system derived by Kohl and King (1967). The winds produce a marked effect on the daily variation of electron density, $N(t)$, with midday 'biteouts' much as observed. Sterling et al. (1969) found in their results a late evening 'trench' at dip latitudes $20^{\circ}-30^{\circ}$, attributed both to the downward drift in the outer part of the fountain and to winds, which finds a counterpart in the observational data. Unlike the midlatitude F2-layer, where lunar tidal effects are weak, if detectable at all, the equatorial F2-layer has distinct features that are systematically related to lunar local time (McNish and Gautier, 1949).

At night, when photoionization is drastically reduced (and comes only from starlight, or from sunlight scattered in the interplanetary medium), lifting by an equatorward wind becomes more effective than crossequator transport, opposite to the situation in daylight. Nighttime converging winds and the 'reverse fountain' (Sect. 2.4) help to maintain the equatorial F2-layer. The drifts and winds around sunset are crucial to the survival of the daytime ionization into the night; upward drift helps to provide a large post-sunset electron density. There is no protonospheric reservoir that could in principle sustain the nighttime equatorial ionosphere, as exists at midlatitudes.

\subsection{How the equatorial trough depends on the electric field}

The day-to-day relationship between the size of the equatorial trough, and the electric field that causes it, was investigated by Dunford (1967). Using as a parameter the product of the 'depth' of the trough (expressed as a fraction of the equatorial $N \mathrm{mF} 2$ at the equator), and the 'width' (expressed as the crest-totrough latitudinal distance), both determined from topside soundings by the satellite Alouette 1, he found very significant correlations between this product and the daily magnetic range at observatories in the equatorial zone. As the daily magnetic range indicates the strength of the daytime ionospheric electric current, which is related to the ambient electric field, these correlations provide evidence to support Martyn's (1947) fountain theory.

The electrojet has considerable day-to-day variability, with days of 'weak electrojet' on which both the midday 'noon biteout' in the $N(t)$ variations and the latitudinal trough are weaker, and may disappear on days of occurrence of the more spectacular 'reverse electrojet' or 'counter electrojet' (Rajaram and Rastogi, 1974) (equatorial sporadic E may disappear too).

\subsection{The semiannual variation of $\mathrm{NmF2}$ and $\mathrm{hmF} 2$}

Annual and semiannual variations in the F2-layer, particularly the latter, still present something of a problem (but see Sect. 4.2). Their morphology has long been studied with the aid of ionosonde data. Yonezawa (1967) used extensive data from two stations within $1^{\circ}$ of the geomagnetic dip equator but in opposite geographic hemispheres, Huancayo (Peru, $12^{\circ} \mathrm{S}$ ) and Kodaikanal (India, $10^{\circ} \mathrm{N}$ ). He was largely concerned with distinguishing 'seasonal' and 'non-seasonal' influences in the annual variation of $N \mathrm{mF} 2$, which need rather complicated formulas for their description. The semiannual variation is simpler, with consistent peaks in April and October. Reckoning time $t$ in months from mid-December, and omitting the annual term, Yonezawa's (1967) results for sunspot number 100 (corresponding to solar $10.7 \mathrm{~cm}$ flux index of about 150) take the form:

$$
\text { Huancayo: } \begin{aligned}
N \mathrm{mF} 2= & 1.42(1+0.13 \cos (\pi / 3)(t-4.2)) \\
& {\left[10^{12} \mathrm{~m}^{-3}\right] }
\end{aligned}
$$

Kodaikanal: $N \mathrm{mF} 2=1.36(1+0.09 \cos (\pi / 3)$

$$
(t-4.3))\left[10^{12} \mathrm{~m}^{-3}\right]
$$

As solar activity varies over the sunspot number range 0-200 (corresponding to the range 70-240 of solar 10.7 flux index), the semiannual/mean ratio stays in the range $0.09-0.15$ (tending to be larger at solar minimum) and the phase stays constant to within \pm 0.2 month, even though the annual mean of $N \mathrm{mF} 2$ increases nearly fourfold.

A semiannual variation of $h \mathrm{mF} 2$, with maxima soon after equinox, was detected at Lindau $\left(52^{\circ} \mathrm{N}\right)$ (Becker, $1967)$ and Puerto Rico $\left(18^{\circ} \mathrm{N}\right)$ (Yonezawa, 1973). Calculations with published values of the M3000 propagation factor at Huancayo, using a formula of Shimazaki (1955) which gives approximate values of $h \mathrm{mF} 2$, show a similar semiannual variation of $h \mathrm{mF} 2$. Its amplitude is about $3 \mathrm{~km}$ at solar minimum, increasing to about $10 \mathrm{~km}$ at solar maximum (Th. Ulich, personal communication, 1998). There is some doubt as to the absolute accuracy of the 'Shimazaki formula' in the 
Table 1. Height of the F2 peak at Huancayo, computed from the data of Croom et al. (1959)

\begin{tabular}{llll}
\hline Month & $\begin{array}{l}\text { Number of } \\
\text { values }\end{array}$ & $\begin{array}{l}\text { Mean } \\
h \mathrm{mF} 2(\mathrm{~km})\end{array}$ & $\begin{array}{l}\text { Mean sunspot } \\
\text { number }\end{array}$ \\
\hline $\begin{array}{l}\text { Solar minimum } \\
\text { December 1944 }\end{array}$ & 28 & 342 & 28 \\
March 1944 & 11 & 336 & 11 \\
June 1944 & 5 & 331 & 5 \\
Solar maximum & & & \\
$\quad$ December 1938 & 93 & 442 & 93 \\
March 1939 & 65 & 399 & 65 \\
June 1939 & 101 & 377 & 101 \\
\hline
\end{tabular}

equatorial ionosphere, but a systematic semiannual variation should be correctly represented.

To investigate further, the present author has examined $N(h, t)$ electron density distributions for Huancayo, computed by Croom et al. (1959) for a selection of magnetically quiet days near solstice and equinox in 1938/1939 (solar maximum) and 1944 (solar minimum). Taking all available values for 10-14 LT (the number of values per month varies between 15 and 45) the averages are as shown in Table 1.

Within each month, the standard deviations are about $25 \mathrm{~km}$. As solar activity was appreciably lower in March 1939 than in the neighbouring solstice months, the March 1939 value of $h \mathrm{mF} 2$ might be raised by $10 \mathrm{~km}$ or so to compensate for that. Even then, the data give no real evidence of a semiannual variation, either in 1938/ 1939 or in 1944. The phase cannot be determined from so few data. More analysis of the variations of $h \mathrm{mF} 2$ at equatorial latitudes is called for.

\section{Some outstanding problems}

\subsection{Longitude variations}

Notwithstanding the discussion of asymmetries in Sect. 3.2, it is not clear whether the simple picture of transequatorial winds accounts for all the differences between longitude sectors. It seems worth asking why there should be variations with longitude in the equatorial F-layer at all, even given the offset of the geomagnetic field from geographic coordinates. The consequences of the offset include:

(a) Seasonal asymmetries of solar zenith angle, which as mentioned previously have some effect in the Asian and South American sectors where the dip and geographic equators are most separated;

(b) Declination effects, which occur because the thermospheric wind patterns are mainly geographically controlled. As the wind-produced drift $\mathbf{V}_{\mathrm{W}}$ (Eq. 6) is aligned in the magnetic meridian, its local time variation is influenced by magnetic declination, much as described for midlatitudes by Kohl et al. (1969), with consequent effects on the local time variation of $N \mathrm{mF} 2$; (c) Some distortion of the magnetic field geometry from an exact offset dipole, which results in secondorder corrections to the diffusion and drift equations;

(d) Greater penetration of energetic particles in the American sector, the geomagnetic field being 30\% weaker than in the Asian sector.

Apart from (a), none of these seems likely to amount to much in the daytime F2-layer.

\subsection{Influences of the general thermospheric circulation on the equatorial $F$ layer}

The transequatorial winds, mentioned in connection with north-south asymmetries (Sect. 3.2), are part of the general thermospheric circulation. This circulation appears to provide the best available explanation of the semiannual variations described in Sect. 3.5. According to Fuller-Rowell (1998), the global thermosphere is more 'stirred' at the solstices than at the equinoxes. Briefly, the prolonged input of solar energy in the summer hemisphere produces a greater degree of mixing worldwide, which results in a greater mean molecular mass, in other words, a smaller atomic/molecular ratio, in the thermosphere as a whole, at solstice as compared with equinox. Modelling by Rishbeth et al. (2000) does indeed show that, at solstice, the prevailing summer-towinter wind transports more molecular gas into the low latitude thermosphere than is present in the symmetrical equinox situation. Given the well-known link between the neutral atomic/molecular ratio and F2-layer electron density, this seems a likely explanation of the semiannual variation. The wind patterns show variations with longitude, due to the configuration of the geomagnetic field, which may contribute to the equatorial longitude variations mentioned in Sect. 4.1.

\subsection{Auroral-zone influences}

The magnetic asymmetries may affect the equatorial F-layer in another way, through influences transmitted from the auroral zones. On plotting the positions of the quiet-day auroral ovals, as given by the model of FullerRowell and Evans (1987), it is found that the distance (in latitude) between the north and south daytime ovals is $12^{\circ}$ less in eastern (Asian/Australian) longitudes than in western (Atlantic/American) longitudes. This difference produces some differences in the quiet-day thermospheric circulation, and may cause a greater susceptibility to magnetic disturbance in the eastern sector than in the western.

Another factor that also depends on the geometry of the auroral ovals is the transmission of atmospheric gravity waves from high latitudes. Fuller-Rowell et al. (1994) modelled the propagation of opposing wave trains, launched from the northern and southern auroral ovals during the active phase of a magnetic storm. The wave fronts meet and cross, though any effects on the equatorial F-layer are transient. A different aspect is 
the much more rapid process of transmitting electric fields. An example of rapid transmission of an electric field perturbation, following a northward turning of the interplanetary magnetic field, was described by Kelley et al. (1979). The effect was observed practically simultaneously by three incoherent scatter radars in the American sector, Chatanika $\left(65^{\circ} \mathrm{N}\right)$ in the auroral zone, Millstone Hill $\left(43^{\circ} \mathrm{N}\right)$ at a subauroral latitude, and Jicamarca $\left(12^{\circ} \mathrm{S}\right)$ on the magnetic equator.

\subsection{The equatorial 'trough' in the neutral thermosphere}

An equatorial trough in the neutral air density was discovered by Hedin and Mayr (1973) from the data of the neutral particle mass spectrometer aboard the OGO-6 satellite. This trough has some resemblance to the F2-layer trough, in that it occurs at all longitudes and is prominent in the evening and absent in the early morning. Possible explanations include (a) heating by precipitated energetic neutral atoms from the radiation belt (Tinsley, 1981), most likely to be significant during storms; (b) photochemical heating, due to the recombination of F2-layer ions and electrons at the 'crests' of the equatorial anomaly (Fuller-Rowell et al., 1997); and (c) ion-drag, produced by the 'fountain' drift of ions away from the equator (Sect. 2.4) (Rishbeth, 1979).

A related 'equatorial wind and temperature anomaly' exists in the latitudinal variation of temperature and zonal winds, as measured by the Wind and Temperature Spectrometer and Langmuir Probe aboard the DE-2 satellite (Raghavarao et al., 1991, 1998). At the dip equator, there are minima of electron density and neutral temperature, maxima of zonal wind speed (eastward at $19 \mathrm{LT}$, westward at $11 \mathrm{LT}$ ); about $25^{\circ}$ from the dip equator, there are maxima of electron density and neutral temperature, minima of zonal wind speed. The explanation of these features, in terms of a meridional circulation cell with accompanying adiabatic heating and cooling (Raghavarao et al., 1993), is called into question by the 'coupled model' calculations of Fuller-Rowell et al. (1997), who invoke instead chemical heating from the recombination of $\mathrm{O}^{+}$ions. The wind explanation seems to be supported by the observations of Meriwether et al. (1985), who observed depletions of the red $\lambda 6300$ airglow around 22 LT at Arequipa, Peru $\left(16^{\circ} \mathrm{S}\right.$, just south of the dip equator), which they attributed to the plasma lifting produced by the equatorward winds associated with the meridional anomaly (see Eq. 6) . The Arequipa results recall the pioneering work of Barbier (1957) in equatorial Africa, who discovered a relation between the intensity $J$ of the $\lambda 6300$ night airglow and F2-layer electron density and virtual height $h^{\prime} \mathrm{F}$ which, in the equatorial zone by night, is thought to represent the height of the bottom of the lower F2-layer quite well. It takes the form (with $k_{1}$ and $k_{2}$ as empirical constants)

$J(6300)=k_{1}+k_{2}(N \mathrm{mF} 2) \exp \left[\left(200-h^{\prime} \mathrm{F}\right) / H\right]$
4.5 Zonal winds, superrotation, and the nighttime wind anomaly

Consider the equation for the zonal wind $U_{\mathrm{x}}$, derived from Eq. (8). Near the equator (so no Coriolis term), and omitting the tidal term and simplifying the viscosity term, it takes the form

$$
\begin{aligned}
\mathrm{d} U_{\mathrm{x}} / \mathrm{d} t & \equiv \partial U_{\mathrm{x}} / \partial t+U_{\mathrm{x}} \partial U_{\mathrm{x}} / \partial x \\
& =F_{\mathrm{x}}+K N\left(V_{\mathrm{x}}-U_{\mathrm{x}}\right)+(\mu / \rho)(\partial / \partial h)^{2} U_{\mathrm{x}}
\end{aligned}
$$

An interesting problem, which is reserved for a future paper so will only be outlined here, is posed by the changes of inclination detected by precise measurements of the orbits of artificial satellites. These changes, small but systematic, are attributed to a net eastward motion in the thermosphere, of order $100 \mathrm{~m} \mathrm{~s}^{-1}$, alternatively described as a superrotation of about $20 \%$ (King-Hele, 1964). Adopting the early picture of a simple day/night pattern of the zonal pressure gradient $F_{\mathrm{x}}$, as portrayed by early models, superrotation could be explained in terms of nighttime polarization fields, that move the plasma eastward, thus reducing considerably the iondrag term $K N\left(V_{\mathrm{x}}-U_{\mathrm{x}}\right)$ in Eq. (16). This causes the nighttime (eastward) winds to blow faster than the daytime (westward) winds, giving the required superrotation (e.g., Heelis et al., 1974).

However, results from the Neutral Atmosphere Temperature Experiment aboard the AE-E satellite, at heights near $275 \mathrm{~km}$, show that the daily thermospheric variation at low latitudes is not as simple as assumed by Heelis et al. (1974). There are temperature maxima at night, sometimes exceeding the afternoon temperatures (Spencer et al., 1979), apparently associated with the equatorial wind and temperature anomaly referred to in Sect. 4.4.

Evaluating the terms in Eq. (16), Herrero et al. (1985) verified that the zonal momentum balance is well satisfied by the zonal winds measured by the DE-2 Wind and Temperature Spectrometer. But the daily mean component of these winds is only about $20 \mathrm{~m} \mathrm{~s}^{-1}$, corresponding to $4 \%$ superrotation (Wharton et al., 1984). The validity of the satellite orbital method was reiterated by King-Hele and Walker (1988). What went wrong?

\subsection{Topographical influences?}

Another factor, perhaps an important one, is the topography of the underlying surface and its effects in the lower atmosphere. There are intriguing east-west asymmetries in E-layer drifts, measured at Jicamarca with the radar beam pointing eastward over the Andes and then westward over the Pacific (Balsley, 1977). The asymmetries were tentatively attributed to non-uniform zonal winds that might be related to the different surface regimes. Moreover, there are east-west differences in thermospheric temperature and zonal wind, observed from Arequipa in Peru by Meriwether et al. (1997), and attributed to differences in upward energy transport by 
gravity waves, rather than to any electrodynamic effect. In its topography, the South American sector is unique: nowhere else does the magnetic equator cross such a high mountain range. East-west temperature differences have also been reported by optical observations in the very different topography of eastern Brazil (Fagundes et al., 1996), though it is not entirely clear whether these are consistent with the Peruvian data, or even represent the same phenomenon. The full picture of topographic influences remains incomplete, a subject for present and future study.

\section{The future}

For many years, research on the equatorial F-layer, both experimental and theoretical, has focused on the plasma physics, the instability phenomena that produce the intense, small-scale irregular structures of equatorial spread $F$ and sporadic $E$, ranging from metre-size irregularities to the immense 'bubbles' and 'plumes', hundreds of kilometres in size. This trend is likely to continue, with another focus on the middle atmosphere and its connections with even lower levels. Nevertheless, there remains much to be learned about the interactions and positive and negative feedbacks between the plasma and the neutral air, in their composition and their motion, in particular during magnetic storms, which have not been dealt with here.

This work has linked the 1960s to the 1990s by recalling pieces of work, carried out decades ago, that revealed puzzles which are by no means all solved today, and are still relevant to the contemporary scene. A very positive feature of equatorial aeronomy is that it brings together scientists from many countries in South America, Africa, the Indian subcontinent and East Asia, alongside those from the more developed countries.

Acknowledgements. This paper is dedicated to my long-standing colleague Lance Thomas, whose acquaintance I have greatly enjoyed and from whom I have learned much. It reviews a subject to which he contributed, and recalls work that dates back to when he was active in that field. I am grateful to Tudor Jones for the opportunity to write for this special volume. I thank John Meriwether, Bela Fejer, R. Raghava Rao and Arthur Richmond for helpful discussions, and to Thomas Ulich for communicating his results on the semiannual variation of $h \mathrm{mF} 2$.

Topical Editor M. Lester thanks M.C. Kelley and another referee for their help in evaluating this paper.

\section{References}

Abur-Robb, M. F. K., and D. W. Windle, On the day and night reversal in NmF2 north-south asymmetry, Planet. Space Sci., 19, 97-106, 1969.

Appleton, E. V., Two anomalies in the ionosphere, Nature, 157, 691, 1946

Bailey, D. K., The geomagnetic nature of the F2 layer longitude effect, Terr. Magn. Atmos. Elect., 53, 35-39, 1948.

Balsley, B. B., E-region dynamics, J. Atmos. Terr. Phys., 39, $1087-$ 1096, 1977.

Barbier, D., Interprétation de la luminescence nocturne de la raie rouge d'oxygène, Comptes Rendus, Acad. Sciénces Paris, 244, 2077-2080, 1957.
Becker, W., The temperature of the $\mathrm{F}$ region deduced from electron number density profiles, J. Geophys. Res., 72, 2001-2006, 1967.

Bramley, E. N., and M. Peart, Diffusion and electromagnetic drift in the equatorial F2-region, J. Atmos. Terr. Phys., 27, 12011211, 1965.

Bramley, E. N., and M. Young, Winds and electromagnetic drifts in the equatorial F2-region, J. Atmos. Terr. Phys., 30, 99-111, 1968.

Chan, H. F., and G. O. Walker, Computer simulation of the ionospheric equatorial anomaly in East Asia for equinoctial, solar minimum conditions. Part I - Formulation of model, J. Atmos. Terr. Phys., 46, 1103-1112, 1984a.

Chan, H. F., and G. O. Walker, Computer simulation of the ionospheric equatorial anomaly in East Asia for equinoctial, solar minimum conditions. Part II - Results and discussion of wind effects, J. Atmos. Terr. Phys., 46, 1113-1120, 1984 b.

Chiu, Y. T., An improved phenomenological model of ionospheric density, J. Atmos. Terr. Phys., 37, 1563-1570, 1975.

Croom, S. A., A. R. Robbins, and J. O. Thomas, Tables of ionospheric electron density, Watheroo, Maui, Huancayo, Cavendish Laboratory, Cambridge, 1959.

Duncan, R. A., The equatorial F-region of the ionosphere, J. Atmos. Terr. Phys., 18, 89-100, 1960.

Dunford, E., The relationship between the ionospheric equatorial anomaly and the E-region current system, J. Atmos. Terr. Phys., 29, 1489-1498, 1967.

Egedal, J., Daily variation of the horizontal magnetic force at the geomagnetic equator, Nature, 161, 443-444, 1948.

Fagundes, P. R., Y. Sahai, J. A. Bittencourt, and H. Takahashi, Plasma drifts inferred from thermospheric neutral winds and temperature gradients observed at low latitudes, J. Atmos. Terr. Phys., 58, 1219-1228, 1996.

Farley, D. T., Early incoherent scatter observations at Jicamarca, J. Atmos. Terr. Phys., 53, 665-675, 1991.

Fejer, B. G., The equatorial ionospheric electric fields. A review, J. Atmos. Terr. Phys., 43, 377-386, 1981.

Fejer, B. G., Low latitude electrodynamic plasma drifts: a review, J. Atmos. Terr. Phys., 53, 677-695, 1991.

Fejer, B. G., The electrodynamics of the low latitude ionosphere: recent results and future challenges, J. Atmos. Terr. Phys., 59, 1465-1482, 1997.

Ferraro, V. C. A., Diffusion in the ionosphere, Terr. Magn. Atmos. Elect., 50, 215-222, 1945.

Fuller-Rowell, T. J., The "thermospheric spoon": a mechanism for the semiannual density variation, J. Geophys. Res., 103, 39513956, 1998.

Fuller-Rowell, T. J., and D. S. Evans, Height-integrated Pedersen and Hall conductivity patterns inferred from the TIROSNOAA satellite data, J. Geophys. Res., 92, 7606-7618, 1987.

Fuller-Rowell, T. J., M. V. Codrescu, R. J. Moffett, and S. Quegan, Response of the thermosphere and ionosphere to geomagnetic storms, J. Geophys. Res., 99, 3893-3914, 1994.

Fuller-Rowell, T. J., M. V. Codrescu, B. G. Fejer, W. Boror, F. Marcos, and D. N. Anderson, Dynamics of the low-latitude thermosphere: quiet and disturbed conditions, J. Atmos. Terr. Phys., 59, 1533-1540, 1997.

Hanson, W. B., and R. J. Moffett, Ionization transport effects in the equatorial F region, J. Geophys. Res., 71, 5559-5572, 1966.

Heelis, R. A., P. C. Kendall, R. J. Moffett, D. W. Windle, and H. Rishbeth, Electrical coupling of the E- and F- regions and its effect on F-region drifts and winds, Planet. Space Sci., 22, 743-756, 1974.

Hedin, A. E., and H. G. Mayr, Magnetic control of the near equatorial neutral thermosphere, J. Geophys. Res., 78, 16881691, 1973.

Herrero, F. A., H. G. Mayr, N. W. Spencer, A. E. Hedin, B. G. Fejer, Interaction of zonal winds with the equatorial midnight pressure bulge in the Earth's thermosphere: empirical check of momentum balance, Geophys. Res. Lett., 12, 491-494, 1985.

Kelley, M. C., The Earth's ionosphere, Academic Press, San Diego, California, 1989 
Kelley, M. C., and D. L. Hysell, Equatorial spread-F and neutral atmospheric turbulence: a review and comparative anatomy, J. Atmos. Terr. Phys., 53, 695-708, 1991.

Kelley, M. C., B. G. Fejer, and C. A. Gonzales, An explanation for anomalous equatorial ionospheric electric fields associated with a northward turning of the interplanetary magnetic field, Geophys. Res. Lett., 6, 301-304, 1979.

Kendall, P. C., Geomagnetic control of diffusion in the F2 region of the ionosphere. I. The form of the diffusion operator, $J$. Atmos. Terr. Phys., 24, 805-811, 1962.

Kendall, P. C., and W. M. Pickering, Magnetoplasma diffusion at F2-region altitudes, Planet. Space Sci., 15, 825-833, 1977.

King-Hele, D. G., The rotational speed of the upper atmosphere, determined from changes in satellite orbits, Planet. Space Sci., 12, 835-853, 1964

King-Hele, D. G., and D. M. C. Walker, Upper-atmosphere zonal winds from satellite orbit analysis: an update, Planet. Space Sci., 36, 1085-1093, 1988.

Kohl, H., and J. W. King, Atmospheric winds between 100 and $700 \mathrm{~km}$ and their effects on the ionosphere, J. Atmos. Terr. Phys., 29, 1045-1062, 1967.

Kohl, H., J. W. King, and D. Eccles, An explanation of the magnetic declination effect in the ionospheric F2-layer, $J$. Atmos. Terr. Phys., 31, 1011-1016, 1969.

Lyon, A. J., and L. Thomas, The F2-region equatorial anomaly in the African, American and East Asian sectors during sunspot minimum, J. Atmos. Terr. Phys., 25, 373-386, 1963.

McNish, A. G., Institute of Atmospheric and Terrestrial Magnetism and Electricity, Bulletin 10, 271-280, 1937.

McNish, A. G., and T. N. Gautier, Theory of lunar effects and midday decrease in F2 ion-density at Huancayo, Peru, Terr. Magn. Atmos. Elect., 54, 303-304, 1949.

Martyn, D. F., Atmospheric tides in the ionosphere. I. Solar tides in the F2 region, Proc. R. Soc. London, A189, 241-260, 1947.

Meriwether, J. W., M. A. Biondi, and D. N. Anderson, Equatorial airglow depletions induced by thermospheric winds, Geophys. Res. Lett., 12, 487-490, 1985.

Meriwether, J. W., M. A. Biondi, F. A. Herrero, C. G. Fesen, and D. C. Hallenback, Optical interferometric studies of the nighttime equatorial thermosphere: enhanced temperatures and zonal wind gradients, J. Geophys. Res., 102, 20 041-20 058, 1997.

Mitra, S. K., Geomagnetic control of region F2 of the ionosphere, Nature, 158, 668-669, 1946.

Moffett, R. J., The equatorial anomaly in the electron distribution of the terrestrial F-region, Fund. Cosmic Phys., 4, 313-391, 1979.

Namba, S., and K.-I. Maeda, Radio wave propagation, Corona Publishing, Tokyo, p. 86, 1939.

Raghavarao, R., J. N. Desai, B. G. Anandarao, R. Narayanan, R. Sekar, and R. Gupta, Evidence for a large scale electric field gradient at the onset of equatorial spread-F, J. Atmos. Terr. Phys., 46, 355-362, 1984.

Raghavarao, R., L. E. Wharton, N. W. Spencer, H. G. Mayr, and L. H. Brace, An equatorial temperature and wind anomaly (ETWA), Geophys. Res. Lett., 18, 1193-1196, 1991.

Raghavarao, R., W. R. Hoegy, N. W. Spencer, and L. E. Wharton, Neutral temperature anomaly in the equatorial thermosphere - a source of vertical winds, Geophys. Res. Lett., 20, 1027-1030, 1993.

Raghavarao, R., R. Suhasini, W. R. Hoegy, H. G. Mayr, and L. Wharton, Local time variation of equatorial temperature and zonal wind anomaly (ETWA), J. Atmos. Solar-Terr. Phys., 60, 631-642, 1998.

Rajaram, G., Structure of the equatorial F-region, topside and bottomside - a review, J. Atmos. Terr. Phys., 39, 1125-1144, 1977.

Rajaram, G., and R. G. Rastogi, Low-latitude F-region anomalies and the equatorial electric field, Indian J. Radio Space Phys., 3, 323-331, 1974.
Rajaram, G., and P. R. Pisharoty, The Earth's magnetic field, Oxford \& IBH Publishing, New Delhi, Chapter 7, 1998.

Rastogi, R. G., H. Chandra, R. P. Sharma, and G. Rajaram, Ground-based measurements of ionospheric phenomena associated with the equatorial electrojet, Indian J. Radio Space Phys., 1, 119-135, 1972.

Ratcliffe, J. A., The formation of the ionospheric layers F-1 and F-2, J. Atmos. Terr. Phys., 8, 260-269, 1956.

Richmond, A. D., Modeling equatorial ionospheric electric fields, J. Atmos. Terr. Phys., 57, 1103-1115, 1995.

Richmond, A. D., E. C. Ridley, and R. G. Roble, A thermosphere/ ionosphere general circulation model with coupled electrodynamics, Geophys. Res. Lett., 19, 601-604, 1992.

Richmond, A. D., M. Blanc, B. A. Emery, R. H. Wand, B. G. Fejer, R. F. Woodman, S. Ganguly, P. Amayenc, R. A. Behnke, C. Calderon, and J. V. Evans, An empirical model of quietday ionospheric electric fields at middle and low latitudes, J. Geophys. Res., 85, 4658-4664, 1980.

Rishbeth, H., Dynamics of the equatorial F-region, J. Atmos. Terr. Phys., 39, 1159-1168, 1977.

Rishbeth, H., Ion-drag effects in the thermosphere, J. Atmos. Terr. Phys., 39, 885-894, 1979.

Rishbeth, H., A. J. Lyon, and M. Peart, Diffusion in the equatorial F-layer, J. Geophys. Res., 68, 2559-2569, 1963.

Rishbeth, H., I. C. F. Müller-Wodarg, L. Zou, T. J. Fuller-Rowell, G. H. Millward, R. J. Moffett, D. W. Idenden, and A. D. Aylward, Annual and semiannual variations in the ionospheric F2-layer: II. Physical discussion, Ann. Geophysicae, (in press), 2000.

Rüster, R., and J. R. Dudeney, The importance of the non-linear term in the equation of motion of the neutral atmosphere, J. Atmos. Terr. Phys., 34, 1075-1083, 1972.

Shimazaki, T., World-wide variations in the height of maximum electron density of the ionospheric F2-layer, J. Radio. Res. Labs, 2(7), 85-97, 1955.

Spencer, N. W., G. R. Carignan, H. G. Mayr, H. B. Niemann, R. F. Theis, and L. E. Wharton, The midnight temperature maximum in the earth's equatorial thermosphere, Geophys. Res. Lett., 6, 444-446, 1979.

Sterling, D. L., W. B. Hanson, R. J. Moffett, and R. G. Baxter, Influence of electromagnetic drifts and neutral air winds on some features of the F2 region, Radio Sci., 4, 1005-1023, 1969.

Sterling, D. L., W. B. Hanson, and R. F. Woodman, Synthesis of data obtained at Jicamarca, Peru, during the September 11, 1969, eclipse, Radio Sci., 7, 279-289, 1972.

Tinsley, B. A., Neutral atom precipitation - a review, J. Atmos. Terr. Phys., 43, 617-632, 1981.

Thomas, L., The F2-region equatorial anomaly during solstice periods at sunspot maximum, J. Atmos. Terr. Phys., 30, 1631$1640,1968$.

Van Zandt, T. E., R. B. Norton, and G. H. Stonehocker, Photochemical rates in the equatorial F2 region from the 1958 eclipse, J. Geophys. Res., 65, 2003-2009, 1960.

Van Zandt, T. E., W. L. Clark, and J. M. Warnock, Magnetic apex coordinates: a magnetic coordinate system for the ionospheric F2 layer, J. Geophys. Res., 77, 2406-2411, 1972.

Wharton, L. E., N. W. Spencer, and H. G. Mayr, The Earth's thermospheric superrotation from Dynamics Explorer 2, Geophys. Res. Lett., 11, 531-533, 1984.

Woodman, R. F., Vertical drifts and east-west electric fields at the magnetic equator, J. Geophys. Res., 75, 6249-6259, 1970.

Yonezawa, T., On the seasonal, non-seasonal and semi-annual variations in the peak electron density of the F2-layer at noon in the equatorial zone, J. Radio Res. Labs., 14, 1-25, 1967.

Yonezawa, T., Semi-annual variation in the true height of the F2peak in low latitudes (at Puerto Rico), J. Atmos. Terr. Phys., 35, 1181-1186, 1973. 